\title{
Osteopenia in Insulin Treated Diabetes Mellitus
}

\author{
Its Relation to Age at Onset, Sex and Duration of Disease \\ P. McNair ${ }^{1}$, S. Madsbad ${ }^{2}$, C. Christiansen ${ }^{1}$, O. K. Faber ${ }^{2}$, I. Transbøl' ${ }^{3}$, and C. Binder ${ }^{2}$ \\ ${ }^{1}$ Department of Clinical Chemistry, Glostrup Hospital, Glostrup, ${ }^{2}$ Hvidøre Hospital, Klampenborg, and ${ }^{3}$ Division of Endocrinology, \\ Department of Internal Medicine, Hvidovre Hospital, University Hospital of Copenhagen, Hvidovre, Copenhagen, Denmark
}

Summary. Bone mineral content was measured by photon absorptiometry in 215 insulin treated diabetic out-patients aged 7-70 years. As bone mass increases until the age of 20-25 years, patients were so selected that all remained within the same phase of bone mineral storage throughout the entire course of their diabetes. Other criteria for exclusion were diseases or drugs interfering with mineral metabolism and previous use of oral antidiabetic agents.

As a group the patients demonstrated a bone mineral deficit of $9.8 \%$ compared with sex- and agematched controls $(\mathrm{P}<0.001)$. Comparison between patients who had developed diabetes before the age of 20 years and after that of 25 years revealed deficits of $14 \%$ and $7 \%$, respectively $(\mathrm{P}<0.001)$. Sex differences were not observed.

The initiation of osteopenia seemed to coincide with the onset of clinical diabetes mellitus, and significantly reduced bone mineral content was observed after 2 years of diabetes $(P<0.001)$. After 3-5 years the osteopenia appeared to attain a stable level.

Key words: Bone mineral content, osteopenia, diabetes mellitus.

Early and sporadic observations [1-3] were followed in 1972 by a large-scale radiologic study demonstrating an increased incidence of osteoporosis in diabetes mellitus and an overrepresentation of diabetics among hip fracture patients [4]. Later, photon absorptiometric quantitation of bone mineral content established osteopenia as a general feature of insulin treated diabetes [5,6].

Disagreement exists, however, regarding the development of osteopenia. Thus, Levin et al. [5] considered the osteopenia to be a feature of the underlying disease, being present at the onset of clinical diabetes mellitus, while Ringe et al. [6] concluded that the bone mineral loss is a late complication. The small study populations [5, 6] also gave conflicting or insufficient information concerning the relation of osteopenia to sex and the age at onset of diabetes.

To clarify these problems and to see whether the influence of diabetes mellitus depends on the stage of bone mineral storage we have studied a large group of diabetic out-patients.

\section{Material and Methods}

Among about 1000 insulin treated diabetic out-patients aged 7-70 years who attended Hvidøre Hospital every 3-5 months, 313 were selected according to our criteria (see below). Of these 98 patients declined our invitation leaving 215 patients as the study population.

Our criteria of exclusion were

1. Serum creatinine $>115 \mu \mathrm{mol} / \mathrm{l}$, prior nephrectomy, renal stone disease, urinary incontinence, operations on the digestive tract, pancreas and biliary system, diseases of the liver and pancreas, intestinal malabsorption, endocrine ablations or diseases (other than diabetes), pregnancy or lactation within the last year, malignant diseases, mental or physical disablement, narcomania and alcoholism, and

2. Drugs including hormones (other than insulin), diuretics, anticonvulsants, lithium, neuroleptics, antacids and cytostatic agents known to interfere with bone mineral metabolism or our study conditions.

3. Previous use of oral antidiabetic agents.

4. As bone mass normally increases until the age of 20-25 years (Fig. 1) only patients who remained within either the stage of bone mineral increase or the phase of mature bone mass during the entire course of their diabetes were included.

According to the last criterion the patients were divided into two groups. Group $A$ comprised 86 patients (51 males and 35 females) aged 7-25 years, who developed diabetes between the 
ages of 0 to 20 years. Group B included 129 patients $(92$ males and 37 females) aged $26-70$ years. All were at least 25 years old at the onset of clinical diabetes mellitus.

Average values of groups A and B for age, age at onset, duration of disease and serum creatinine are given in Table 1.

The group of controls comprised 301 children and adolescents ( 145 boys and 156 girls) aged 7-20 years, and 146 adults (54 males and 92 females) aged 21-70 years. None had symptoms of digestive or renal diseases, and all had a normal serum creatinine. The bone mineral content measured in these persons is presented in Fig. 1. Both control subjects and diabetic patients were inhabitants of Copenhagen. Detailed information on the control group has been published previously $[7,8]$.

The measurement of bone mineral content in each patient was calculated as the percentage of mean values in control groups matched for sex and age. For age matching we used two-year agegroups between the ages 7-20 years and 10-year age-groups thereafter.

The bone mineral content was determined by direct photon absorptiometry $[9,10]$. The forearm was fixed in a plexiglass container filled with distilled water. A source of radiation $(25 \mathrm{mCi}$ ${ }^{125} \mathrm{I}$ ) and a detector was placed on each side of the forearm to be examined. As these moved across the arm the transmission of photons through the bones decreased dependent on the bone min-

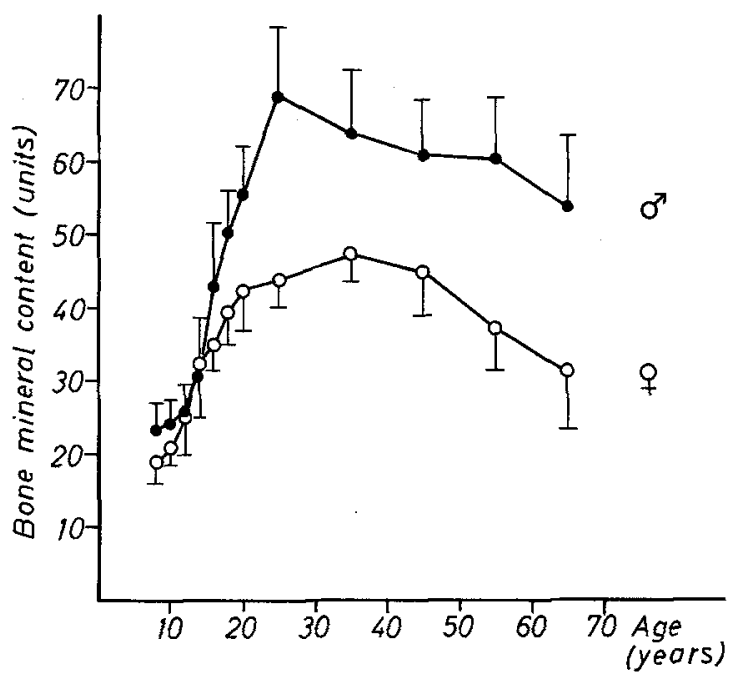

Fig. 1. Bone mineral content as a function of sex and age in 447 normal subjects. In males the storage of bone mineral increases until the age of 25 years; thereafter it declines slowly. In females storage appears to cease at the age of 20 years, after which a plateau is maintained until the onset of the menopause at the age of 45 to 55 years. Following this the bone mineral content decreases. (Each point present mean + or -1 standard deviation) eral content. Because the absorption in plexiglass, distilled water and soft tissue is almost identical the measurement was independent of the amount of soft tissue. The scanner started distally on the forearm, moving $4 \mathrm{~mm}$ proximally between each scan. The first scan to be used was defined as that demonstrating a distance between radius and ulna of $2 \mathrm{~mm}$ or more. The bone mineral content was expressed in arbitrary units as a mean of six scans on each forearm. The coefficient of variation in normal subjects is about $2 \%$. Student's t-test was employed for statistical evaluation of group differences.

\section{Results}

The measurement of bone mineral content and body height in controls and diabetic patients (mean \pm 1 SEM) are presented in Figure 2. The entire series of patients had a bone mineral loss of $9.8 \%$ as compared with controls $(\mathrm{P}<0.001)$. The respective bone mineral content in per cent of normal values in groups $\mathrm{A}$ and $\mathrm{B}$ were $86.1 \pm 1.3 \%$ and $92.9 \pm 1.3 \%$ $(\mathrm{P}<0.001)$. The distribution of the group $\mathrm{A}$ and $\mathrm{B}$ patients in relation to their bone mineral measurements in per cent of normal values are given in Figure 3. A bone mineral loss of more than $10 \%$ occurred in 60 out of 86 patients in group A (70\%) and in 53 of the 129 patients belonging to group B $(41 \%)$. The standard error of this difference $(29 \%)$ is $6.4 \%(\mathrm{P}<$ 0.001). Sex differences of statistical significance were not observed (Table 2). Patients and controls did not

Table 2. Bone mineral content (BMC) in per cent of sex-and agematched controls in relation to sex in group $\mathrm{A}$ and group $\mathrm{B}$ diabetics (see text)

\begin{tabular}{|c|c|c|c|c|}
\hline \multirow[b]{2}{*}{ Group } & \multicolumn{2}{|l|}{ Patients } & \multirow{2}{*}{$\begin{array}{l}\text { BMC } \\
\text { per cent } \\
\text { mean } \pm 1 \text { SEM }\end{array}$} & \multirow{2}{*}{$\begin{array}{l}\text { Significance } \\
\text { of difference }\end{array}$} \\
\hline & Sex & Number & & \\
\hline \multirow{2}{*}{ A } & male & 51 & $86.0 \pm 1.8$ & \multirow{2}{*}{ N.S. } \\
\hline & female & 35 & $86.2 \pm 1.7$ & \\
\hline \multirow{2}{*}{ B } & male & 92 & $94.4 \pm 1.5$ & \multirow{2}{*}{ N.S. } \\
\hline & female & 37 & $89.4 \pm 2.6$ & \\
\hline \multirow{2}{*}{$A+B$} & male & 143 & $91.4 \pm 1.2$ & \multirow{2}{*}{ N.S. } \\
\hline & female & 72 & $87.8 \pm 1.6$ & \\
\hline
\end{tabular}

a $\quad$ N.S. $=$ not significant $(P>0.05)$

Table 1. Average values of age, age at onset of diabetes, duration of disease and serum creatinine in 215 diabetic patients grouped according to age at onset of diabetes (see text)

\begin{tabular}{|c|c|c|c|c|c|c|c|c|c|c|}
\hline \multirow[t]{2}{*}{ Group } & \multicolumn{2}{|c|}{$\begin{array}{l}\text { Number } \\
\text { sex }\end{array}$} & \multicolumn{2}{|l|}{$\begin{array}{l}\text { Age } \\
\text { years }\end{array}$} & \multicolumn{2}{|c|}{$\begin{array}{l}\text { Age at onset } \\
\text { years }\end{array}$} & \multicolumn{2}{|c|}{$\begin{array}{l}\text { Duration } \\
\text { years }\end{array}$} & \multicolumn{2}{|c|}{$\begin{array}{l}\text { Serum creatinine } \\
\mu \mathrm{mol} / 1\end{array}$} \\
\hline & male & female & mean & range & mean & range & mean & range & mean & range \\
\hline A & 51 & 35 & 19 & $7-25$ & 10 & $0-20$ & 8 & $0-22$ & 72 & $44-115$ \\
\hline B & 92 & 37 & 47 & $26-70$ & 36 & $25-67$ & 11 & $0-29$ & 81 & $44-115$ \\
\hline
\end{tabular}


differ respecting body height (Fig. 2). The change of bone mineral content in relation to the duration of diabetes is outlined in Figure 4. Bone mineral content decreases gradually during the first five years and remains stable thereafter. A significant decrease in the bone mineral content is observed after two years duration of diabetes $(\mathrm{P}<0.001)$.
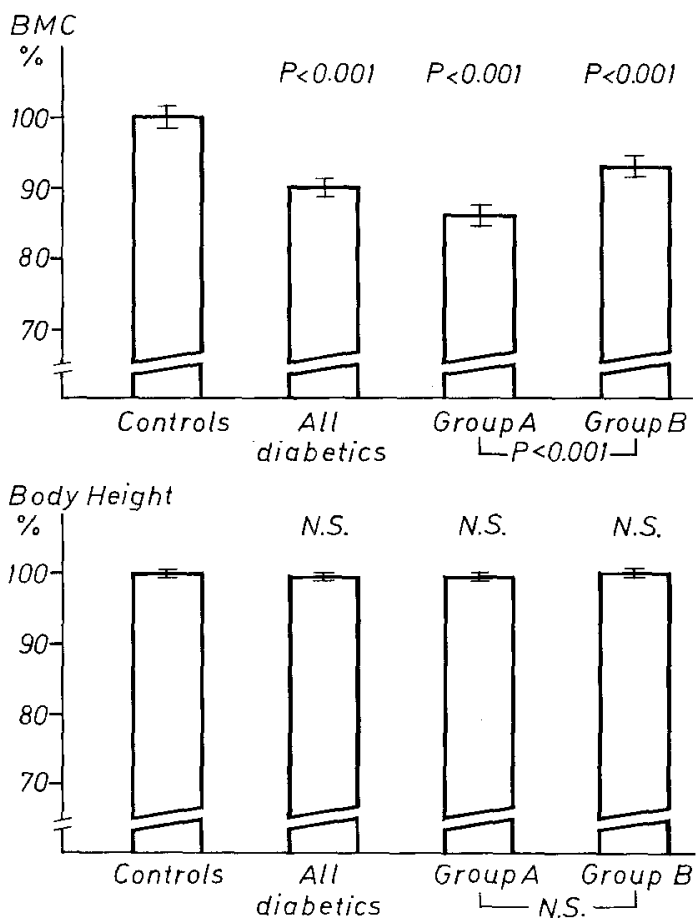

Fig. 2. Bone mineral content (BMC) and body height in per cent of sex- and age-matched controls in 447 control subjects and in 215 diabetic patients grouped according to age at onset and the phase of bone mineral storage (see Fig. 1). Group $A$ comprises 86 patients aged 7-25 years, who developed diabetes between the ages of 0 to 20 years. The 129 patients who form group $B$ were 26-70 years of age. Their diabetes started after the age of 25 years.

\section{Discussion}

We have confirmed earlier reports demonstrating a bone mineral loss of about $10 \%$ in insulin treated diabetic patients $[5,6]$. Since the bone mineral measurements are extremely well correlated with the calcium content of the forearm [9] and also highly

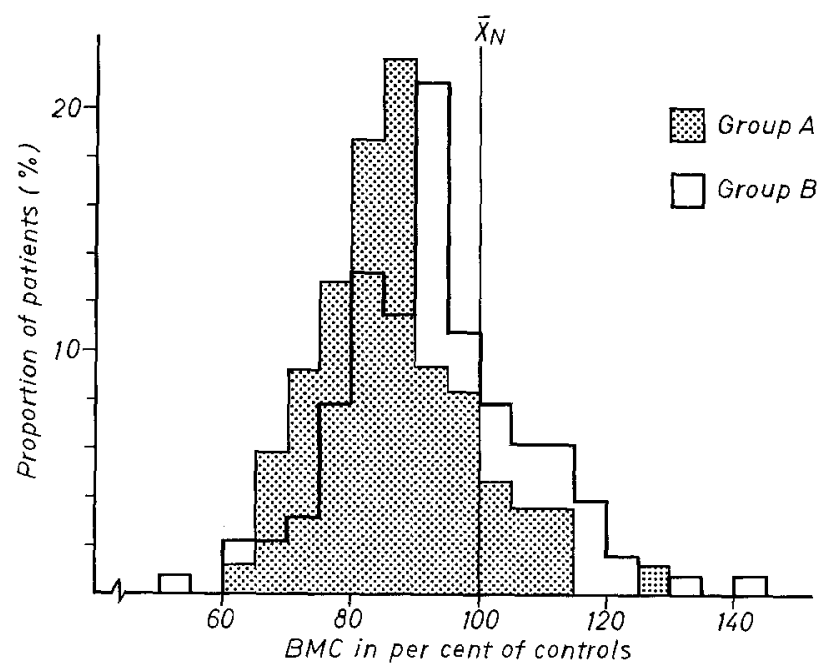

Fig. 3. The distribution of patients in group A and group B (see text) in relation to bone mineral content (BMC) calculated as the percentage of control values matched for sex and age. $\tilde{x}_{N}$ : Normal mean

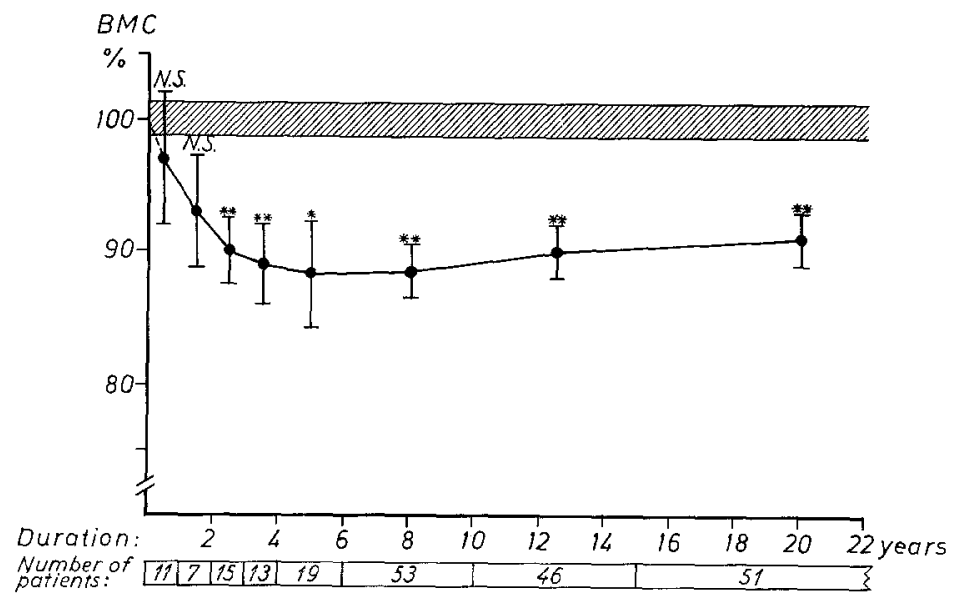

Fig. 4. Relation between bone mineral content (BMC) and duration of diabetes in 215 diabetic patients. Each point presents mean \pm 1 SEM. The hatched area indicates normal mean \pm 1 SEM. N.S. $=$ Non significant $(\mathrm{P}>0.05),{ }^{*} \mathrm{P}<0.01, * * \mathrm{P}<0.001$ 
related to the total body calcium $[11,12]$, it seems reasonable to conclude that diabetic patients have a generalized osteopenia. This condition is present despite normal linear growth of the skeleton, as indicated by our measurements of body height.

The initiation of osteopenia seems to coincide with the onset of clinical diabetes mellitus (Fig. 4). It is noticable that a significant decrease in bone mineral content is detectable after two years of diabetes, at about the same time as the early capillary basement membrane changes become visible by electron microscopy [13]. After three to five years of diabetes the osteopenia appears to attain a stable level at which it remains for the following fifteen years. These observations differ from both of the mutually contradictory reports of Levin et al. [5] and Ringe et al. [6]. This disparity may derive from their small study populations including just a few [5] or no early cases [6], and from the use of different criteria of selection.

Finally, we find that patients who have not completed their bone mineral storage at the onset of diabetes (group A) present a more severe degree of osteopenia than those who have (group B). Unpublished observations by Tougaard and coworkers, demonstrating a positive correlation between bone mineral content and age at onset of diabetes, support this finding, while Levin et al. [5] and Ringe et al. [6] failed to demonstrate differences of statistical significance.

Acknowledgements. This study has been supported by grants from the Danish Hospital Foundation for Medical Research, Region of Copenhagen, Faroe Islands, and Greenland; and the Danish Diabetic Association.

\section{References}

1. Albright, F., Reifenstein, E. C.: Parathyroid glands and metabolic bone diseases: Selected studies, p. 150. Baltimore: Williams and Wilkins Company 1948
2. Hernberg, C. A.: Skelettveränderungen bei Diabetes Mellitus der Erwachsenen. Acta Med. Scand. 143, 1-14 (1952)

3. Kuhlencordt, F,, Wieners, H., Gocke, H.: Skelettuntersuchungen bei Diabetikern bis zum 45. Lebensjahr. Dtsch. Med. Wochenschr. 43, 1913-1916 (1966)

4. Menczel, J., Makin, M., Robin, G., Joye, I., Naor, E.: Prevalence of diabetes mellitus in Jerusalem. Its association with presenile osteoporosis. Isr. J. Med. Sci. 8, 918-919 (1972)

5. Levin, M. E., Boisseau, V. C., Avioli, L. V.: Effects of diabetes mellitus on bone mass in juvenile and adult-onset diabetes. N. Engl. J. Med. 294, 241-245 (1976)

6. Ringe, J.-D., Kuhlencordt, F., Kühnau, J., Jr.: Mineralgehalt des Skeletts bei Langzeitdiabetikern. Densitometrischer Beitrag zur "Osteopathia diabetica". Dtsch. Med. Wochenschr. 101, 280-282 (1976)

7. Christiansen, C., Rødbro, P., Nielsen, C.T.: Bone mineral content and estimated total body calcium in normal children and adolescents. Scand. J. Clin. Lab. Invest. 35, 507-510 (1975)

8. Christiansen, C., Rødbro, P.: Bone mineral content and estimated total body calcium in normal adults. Scand. J. Clin. Lab. Invest. 35, 433-439 (1975)

9. Christiansen, C., Rødbro, P., Jensen, H.: Bone mineral content in the forearm measured by photon absorptiometry. Principles and reliability. Scand. J. Clin. Lab. Invest. 35, 323-330 (1975)

10. Cameron, J. R., Sorenson, J.: Measurements of bone mineral in vivo: An improved method. Science 142, 230-232 (1963)

11. Christiansen, C., Rødbro, P.: Estimation of total body calcium from the bone mineral content of the forearm. Scand. J. Clin. Lab. Invest. 35, 425-431 (1975)

12. Mazess, R. B.: Estimation of bone and skeletal weight by direct photon absorptiometry. Invest. Radiol. 6, 52-60 (1971)

13. Østerby, R.: Early phases in the development of diabetic glumerolopathy. A quantitative electron microscopic study. Acta Med. Scand. [Suppl.] 574, 1-82 (1974)

Received: November 10, 1977, and in revised form: March 10,1978

Dr. P. McNair

Department of Clinical Chemistry

Glostrup Hospital

DK - 2600 Glostrup/Copenhagen

Denmark 